\title{
ESTUDO DA REGULAÇÃO GÊNICA DE IL-17A e IFNy EM CÉLULAS TCD4 ENCEFALITOGÊNICAS DỦRANTE A EVOLUÇÃO DA ENCEFALOMIELITE EXPERIMENTAL AUTOIMUNE INDUZIDA EM CAMUNDONGOS C57BL/6.
}

\author{
Camila O. Vaz ${ }^{\star}$ Fernando Pradella , Bruna Campos, Rani Cocenza, Alessandro S. Farias.
}

\begin{abstract}
Resumo
A Esclerose Múltipla (EM) é uma doença crônica e desmielinizante do sistema nervoso central (SNC). A encefalomielite autoimune experimental (EAE) é o modelo experimental da EM. A EAE é uma doença autoimune mediada por linfócitos T CD4+ encefalitogênicos Th1 e/ou Th17, que atuam de forma sinérgica durante o desenvolvimento da EAE. Entretanto, recentemente, demonstrou-se que células Th17 passam a expressar prioritariamente IFNy logo após infiltrarem-se no SNC. Isto é, a célula encefalitogênica é Th1 e Th17, mas em diferentes momentos da doença1. Resultados prévios do nosso laboratório mostraram que as células T CD4 infiltradas no sistema nervoso central apresentam um perfil e ação citotóxicos. Dessa forma, nessa proposta, pretende-se avaliar a regulação gênica de IL-17 e de IFNy durante a montagem da resposta citotóxica em camundongos C57BL/6 com EAE e verificar se o perfil citotóxico é construído a partir de células que inicialmente expressavam apenas IL-17.
\end{abstract}

\section{Palavras-chave:}

IL-17, IFNy, Citotoxicidade de células TCD4.

\section{Introdução}

A Esclerose Múltipla (EM) é uma doença crônica e desmielinizante do sistema nervoso central (SNC). A encefalomielite autoimune experimental (EAE) é extensivamente aceita como o modelo experimental da EM. A EAE é uma doença autoimune mediada por linfócitos $\mathrm{T} \mathrm{CD}^{+}$. Esses linfócitos $\mathrm{T} \mathrm{CD}^{+}$ encefalitogênicos foram primeiramente descritos como subpopulações Th1, produtores de IFNy. Contudo, estudos subsequentes demonstraram o papel importante das Th17 (T CD4 produtoras de IL-17) na EAE, levando à crença de que as subpopulações Th1 e Th17 agem de maneira sinérgica. Recentemente, foi mostrado que os linfócitos Th17 encefalitogênicos "desligam" a expressão de IL-17 e passam a expressar prioritariamente IFN $\gamma$ logo após infiltrarem no SNC. Resultados prévios do nosso laboratório mostraram que as células T CD4 encefalitogênicas constroem um perfil citotóxico. Dessa forma, nessa proposta, pretende-se avaliar a regulação gênica de IL-17 e de IFN $\gamma$ durante a montagem da resposta citotóxica em camundongos C57BL/6 com EAE e verificar se o perfil citotóxico é construído a partir de células que inicialmente expressavam apenas IL-17.

\section{Resultados e Discussão}

Nossos resultados mostraram que a maior parte das células infiltradas no SNC são produtoras de IFNy, corroborando estudo recente que diz que as células $\mathrm{T}$ CD4 se tornam produtoras de IFNy uma vez que infiltram o SNC. Ainda, a expressão de moléculas relacionadas à citotoxicidade é significativamente aumentada em células produtoras de IFNy em relação às que expressam IL-17. Esses resultados também se repetem em células $\mathrm{T}$ CD4+CD8+ infiltradas no SNC. Aparentemente, o aumento da expressão de IFNy está diretamente relacionado com a construção do perfil citotóxico pelas células T CD4 encefalitogênicas.

\section{Conclusões}

A expressão de moléculas relacionadas à citotoxicidade é significativamente mais alta em células $\mathrm{T}$ CD4+ produtoras de IFN $\gamma$. Nossos resultados corroboram um trabalho recente que mostra que quase todas as células $\mathrm{T}$ CD4+ produtoras de IFN $\gamma \mathrm{CD} 4+$ infiltradas no SNC de animais com EAE eram produtoras de IL-17a na periferia ${ }^{1}$. Assim, células $\mathrm{T}$ CD4+ citotóxicas produtoras de IFN $\gamma$ encontradas no $\mathrm{SNC}$ e as produtoras de IL-17a na periferia devem representar a mesma população, mas em estágios efetores diferentes. Ainda, uma vez que o IFN $\gamma$ está downstream dos fatores de transcrição para citotoxicidade, a conversar de Th17 em Th1-like é provavelmente um "efeito colateral" da construção do perfil citotóxico.

\section{Agradecimentos}

Ao CNPQ e FAPESP pelo suporte financeiro. 